\title{
SURFACE HARDENING AND WEAR CORRELATIONS STUDIES WHEN TURNING INCONEL 718
}

\author{
P. Jeyapandiarajan ${ }^{1}$, M. A. Xavior ${ }^{2 *}$, N. C. Sasidharan ${ }^{3}$, A. Duchosal ${ }^{4}$ \\ 1,2 School of Mechanical Engineering, VIT, Vellore 632014, India \\ ${ }^{3,4}$ Université François Rabelais de Tours, Tours 37200, France \\ *Corresponding author; e-mail: manthonyxavior@vit.ac.in
}

\begin{abstract}
Machining is one of the stochastic processes, in which, the work specimen is exposed to rigorous plastic deformation which, results in rapid increase in work hardening effect and affects the life of the cutting tool particularly for Inconel 718. The depth and degree at which machined surface harden depends on factors like material properties, tool composition and tool dimensions, tool condition, cutting environment and cutting parameters. This article aims to study the work hardening effect and flank wear while machining in different conditions with different cutting tools. Further, it is important to correlate the cutting velocity and tool wear with wok hardening effect. Experimentation was carried out on Inconel 718 in a CNC lathe machine under various machining conditions namely dry, minimum quantity lubrication and flood cooling using different tools namely PVD coated TiAIN, Ceramic (70\% Al2O3 + 30\% TiC) and cBN having same tool dimensions.
\end{abstract}

\section{Keywords:}

Inconel 718; Machining; Work hardening; Cutting tool; Tool wear

\section{INTRODUCTION}

Inconel 718 is referred as nickel chromium alloy with superior corrosion resistant and high-strength properties between the operating temperatures of $-252^{\circ} \mathrm{C}$ to $704^{\circ} \mathrm{C}$. Inconel 718 provides combination of good tensile, fatigue and rupture strength as result it is used in wide range of applications such as aerospace, gas turbines cryogenic tanks, ships and chemical industries. Machining is considered to be a stochastic process which involves both type of deformation namely elastic and plastic. While machining the surface of work material are subjected to sever plastic deformation and this plastic deformation results in rapid increase in hardness of bulk material. The depth and degree at which machined surface harden depends on factors like work material chemical composition, tool material, tool geometry, tool condition, cutting conditions and cutting parameters[1]. Plastic deformation is introduced because of the friction that occurs due to the physical contact between the flowing chip and rake face of the tool and also between the work surface and the flank face of the tool. [2]

When cutting tool approaches the work material with high cutting pressure on small elemental area, the exposed area of the work material encounters plastic deformation, as a result, it stretches the crystal grains. As the machining process progresses, the grains expands further and the elemental area narrows around the tool edge and subsequently the element gets detached as a chip from surface of work material. During plastic deformation strain rate is very high which generates very high temperatures (approx. $600-800^{\circ} \mathrm{C}$ ) [3]. The properties of material are altered during machining i.e deformation at low temperature relative to its melting temperature, not all but some properties like tensile strength; yield strength and hardness gets affected during machining of super alloys. This change in mechanical properties are one of the most important area for researchers as it has great importance in industrial practices. The rate at which material hardens during machining influences both power required and subsequent processing on work material[4].

One of the primary parameter to evaluate the machining performance is the wear encountered by the tool. In order to obtain better machining performance choosing the correct tool material and machining conditions plays a significant function. Cutting tool selection includes tool material, geometry and types of coating [5]. Tool material should reveal good resistance to wear, high hot hardness, high toughness and strength and better chemical stability. Adhesion and work hardening are associated with sever notching at the cutting edge of the tool and machined surface of the work material. These two effects are considered to be the predominant failure mode during turning of super alloys with carbide tool. Abrasion which occurs at the flank face of the tool induces wear, chipping and catastrophic failure [6].

Many research studies have been reported in literatures addressing the issue regarding work hardening, plastic deformation and alteration of machined surface. The hardness of machined surface was found to be more across the subsurface of the specimen, where the temperature and 
strain were neutralised for bulk material [7]. Increase in machining speed and depth decreases the depth of work hardening in turning of Inconel718 [8]. With increase in feed and machining depth, microhardness increases on both surface and subsurface area [9]. The current work is focused on investigation of work hardening behaviour and the influence of cutting velocity, tool material and machining conditions on micro hardness and flank wear during turning of Inconel718.

\section{MATERIAL AND METHODS}

Inconel 718 has austenitic face centered cubic (FCC) microstructure, a continuous matrix phase known as gamma $(Y)$ phase that usually contains disordered solid solution elements like Chromium, Tungsten, Cobalt and Molybdenum. The primary strengthening phase is Ni3(AITi) called as gamma prime ( $\left.\gamma^{\prime}\right)$, other strengthening phase present is Ni3Nb called gamma double prime ( $\left.\gamma^{\prime \prime}\right)$. Both gamma prime and gamma double prime strengthening phase precipitate as separate grains. Further, the presence of primary carbide particles like niobium and titanium carbide is evident in Inconel 718 [10]. The work material dimensions used for experimentations are of $40 \mathrm{~mm}$ diameter and $120 \mathrm{~mm}$ long. The $\mathrm{Wt} \%$ of the major elements available in Inconel 718 is shown in Table - 1 [11]. The mechanical properties of Inconel 718 used in this research work have a hardness of $30 \mathrm{HRc}$, density: $8.19 \mathrm{~g} / \mathrm{cm} 3$ and Young's modulus: 206 GPA. The critical dimensions of the cutting tool used for conducting the machining experiments are shown in Table-2. Two levels of cutting speeds namely 100 and $150 \mathrm{~m} / \mathrm{min}$ along with three tool materials namely carbide, ceramic and $\mathrm{cBN}$ under three machining environment (dry, MQL and flood cooling) were considered for the design of experiments. Table - 3 shows the experimental conditions and the observations recorded are the average value of 5 experimental trails conducted for every combination of parameters. The experiments were conducted to study the influence of cutting speed (Vc), tool materials and cutting conditions on tool wear and work hardening after machining. Tool wear studies are reported after turning a fixed interval i.e $60 \mathrm{~mm}$ for all the tool inserts. All experiments were carried on automatic CNC turning centre which houses a 14KVA motor drive and a variable spindle system with speeds varying between 50 and 4000 rpm. The experiments were designed and conducted according to Taguchi L18 orthogonal array. Fig 1 presents experimental setup used in this research work for conducting the machining trials. Constant feed rate of $0.15 \mathrm{~mm} / \mathrm{rev}$ and depth of cut: $0.5 \mathrm{~mm}$ are maintained for conducting the machining trials.

Tab. 1: Wt\% of major elements in Inconel-718.

\begin{tabular}{cc}
\hline Elements & $\mathrm{Wt} \%$ \\
\hline Nickel & $50-55$ \\
Chromium & $17-21$ \\
Molybdenum & 3.05 \\
Iron & $18-24$ \\
Others & Balance \\
\hline
\end{tabular}

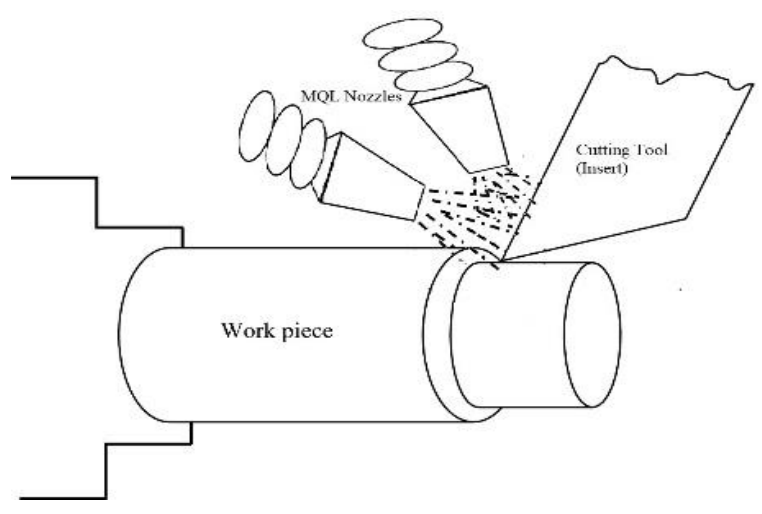

Fig. 1: Experimental setup.

Tab. 2: Work material properties and the tool geometry.

\begin{tabular}{|c|c|c|c|}
\hline \multicolumn{2}{|l|}{ Material } & \multicolumn{2}{|c|}{ Tool Geometry } \\
\hline $\begin{array}{c}\text { Work } \\
\text { material }\end{array}$ & $\begin{array}{l}\text { Inconel - } \\
718\end{array}$ & Inclination angle & $-6^{\circ}$ \\
\hline Hardness & $\begin{array}{c}30+-1 \\
\text { HRC }\end{array}$ & $\begin{array}{c}\text { Orthogonal rake } \\
\text { angle }\end{array}$ & $-6^{\circ}$ \\
\hline Size & $\phi 40 \mathrm{~mm}$ & $\begin{array}{c}\text { Orthogonal } \\
\text { clearance angle }\end{array}$ & $6^{\circ}$ \\
\hline Density & $8.19 \mathrm{~g} / \mathrm{cm}^{3}$ & $\begin{array}{l}\text { Principal cutting } \\
\text { edge angle }\end{array}$ & $95^{\circ}$ \\
\hline $\begin{array}{l}\text { Young's } \\
\text { modulus }\end{array}$ & 206 GPA & Nose radius & $\begin{array}{l}0.8 \\
\mathrm{~mm}\end{array}$ \\
\hline
\end{tabular}

Tab. 3: Experimental Observations.

\begin{tabular}{|c|c|c|c|c|}
\hline $\begin{array}{c}\text { Cuttin } \\
\text { g } \\
\text { Speed }\end{array}$ & $\begin{array}{c}\text { Machining } \\
\text { Environment }\end{array}$ & $\begin{array}{c}\text { Tool } \\
\text { Material }\end{array}$ & $\begin{array}{c}\text { Surface } \\
\text { Micro- } \\
\text { hardness } \\
(\mathrm{HV})\end{array}$ & $\begin{array}{c}\text { Vb } \\
\text { Max. } \\
(\mu \mathrm{m})\end{array}$ \\
\hline 100 & Dry & Carbide & 420.1 & 54.0 \\
\hline 100 & Dry & ceramic & 344.5 & 42.4 \\
\hline 100 & Dry & cBN & 400.6 & 74.0 \\
\hline 100 & MQL & Carbide & 364.2 & 57.8 \\
\hline 100 & MQL & ceramic & 401.9 & 33.1 \\
\hline 100 & MQL & cBN & 379 & 41.5 \\
\hline 100 & Flood & Carbide & 435.9 & 69.3 \\
\hline 100 & Flood & Ceramic & 386.8 & 65.7 \\
\hline 100 & Flood & cBN & 411.4 & 93.5 \\
\hline 150 & Dry & Carbide & 427.9 & 78.0 \\
\hline 150 & Dry & ceramic & 391.2 & 44.3 \\
\hline 150 & Dry & cBN & 418.9 & 94.8 \\
\hline 150 & MQL & Carbide & 373.6 & 56.3 \\
\hline 150 & MQL & ceramic & 369.4 & 31.6 \\
\hline 150 & MQL & cBN & 357.1 & 42.9 \\
\hline 150 & Flood & Carbide & 420.2 & 110.0 \\
\hline 150 & Flood & ceramic & 405.3 & 69.6 \\
\hline 150 & Flood & cBN & 418.9 & 116.0 \\
\hline
\end{tabular}




\section{RESULTS AND DISCUSSION}

Consequent to experimentations microhardness was measured with Vickers microhardness tester on the surface and subsurface at multiple points on the cross section of machined samples. Tool wear measurements on the tools were measured using optical microscope and SEM images of the cutting edges were analyzed for better understanding of the wear mechanisms.

\subsection{Surface Microhardness Analysis}

The influence of cutting speed, tool material and machining environment on microhardness induced on the machined surface were plotted as shown in Fig. 2. At dry cutting condition it was noted that the microhardness on surfaces increases with an increase in the cutting speed for $\mathrm{cBN}$ and ceramic tool material but there is no significant change while machining with carbide inserts as shown in Fig. 2a. At MQL cutting condition microhardness on the machined surface was observed to decrease with an increase in cutting speed while machining with $\mathrm{cBN}$ and Ceramic tool material, there was no significant change observed in microhardness for carbide tool as shown in Fig. 2b. At flood cooling cutting conditions it has been noted that the surface hardness increases for an increase in cutting speed for all tool materials. For the specimen machined with ceramic tool material minimum microhardness values were recorded which is presented in Fig. 2c.

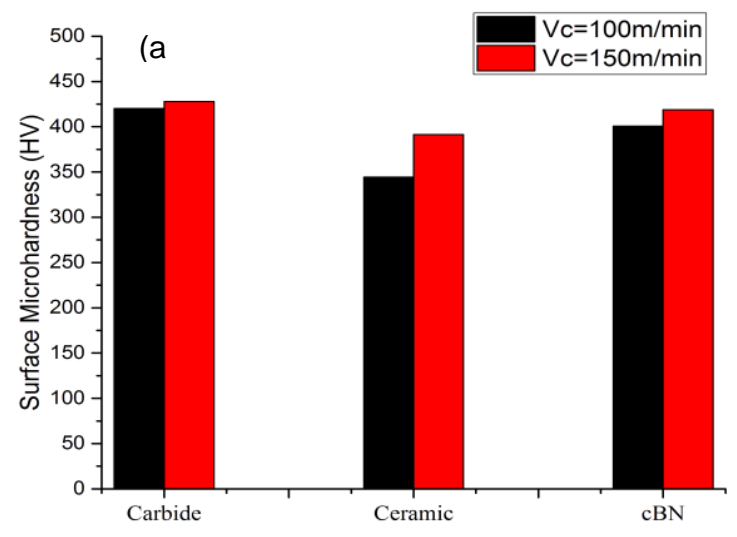

Fig. 2(a): Effect of cutting speed on surface microhardness under Dry cutting conditions.

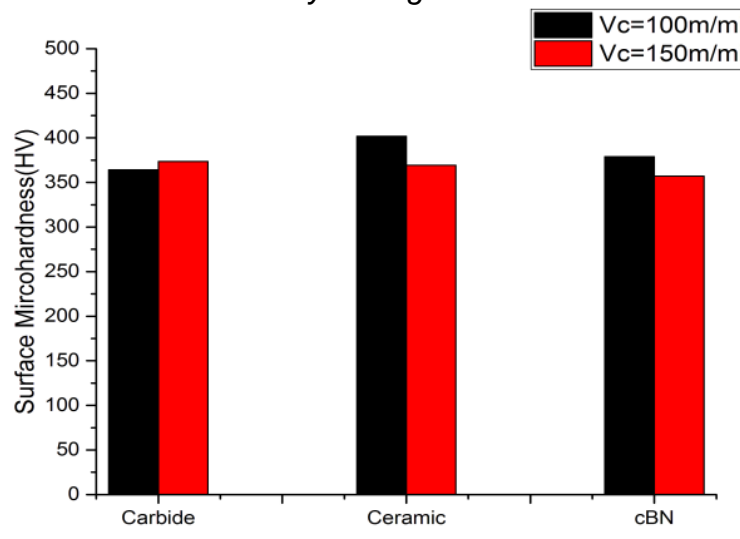

Fig. 2(b): Effect of cutting speed on surface microhardness under MQL cutting conditions.

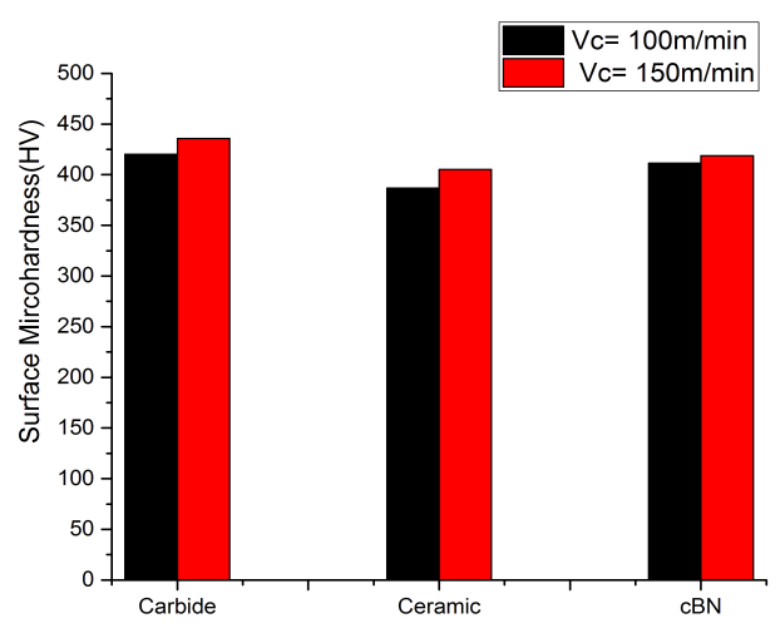

Fig. 2(b): Effect of cutting speed on surface microhardness under Flood cooling cutting conditions.

Figs. 2 a, b \& c indicates that, at all cutting conditions Ceramic tool has shown lowest microhardness value when compared with carbide and $\mathrm{cBN}$ tool. Ceramic tool inserts shows poor thermal conductivity at the cutting zone, further heat generated during machining results in material softening. Material soften has shown lower microhardness shown in fig. 2(a). As the cutting speed increases during dry machining, heat generated at the cutting zone increases at the same time interaction time decreases, chip flow in turn dissipates the major percent of the heat which in turn results in higher microhardnes. This scenario changes with MQL and flood as the lubricants contribute to high heat dissipation provides higher microhardness value. This has lead to higher surface hardness for specimen machined under flood cooling condition and lower microhardness for MQL cutting condition. In Fig. 2 (a \& c) Carbide and cBN has good thermal conductivity property reduces the heat generated at the cutting zone, thermal softening has lower impact on the plastically deformed grains that shows higher surface microhardness.

\subsection{Subsurface Microhardness Analysis}

The work-hardening affinity of nickel alloys under extreme stress creates highly hardened subsurface layer making it very tough for progressive cuts. To rectify this drawback it is stated that constantly wavering depth of cut helps improve machining nickel alloy. The surface and machined subsurface hardness of the work piece is greater than the bulk hardness of the parent material after turning. This proof indicates the work hardening effect while machining and compressive layer is formed. The micro hardness data has been taken at every $0.2 \mathrm{~mm}$ starting from machined surface 0 to $1.8 \mathrm{~mm}$ beneath the machined surface these readings are stopped till bulk hardness of material is reached. High pressures and the heat generated at the machining zone due to the physical contact of the cutting tool with the work material induces a stressed layer of plastically deformed metal on the surface which causes a hardening effect. Fig. 3 illustrates the variations in the microhardness of the work material when subjected to machining under the experimental conditions considered in this research work. 


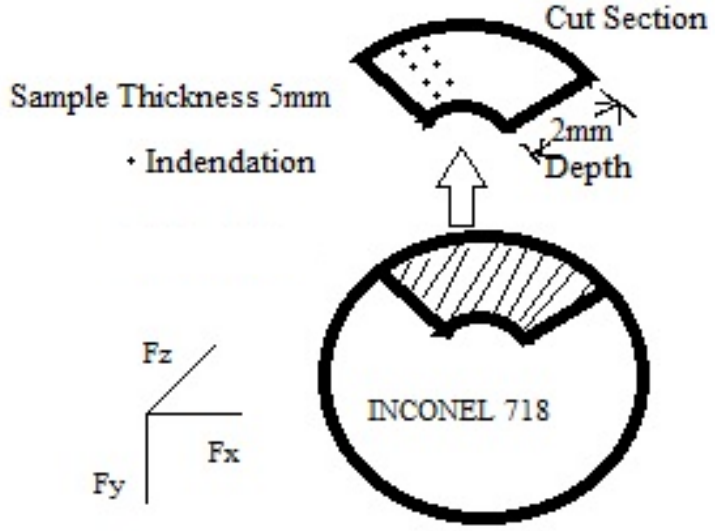

Fig. 3: Subsurface Microhardness measurement on the sample.

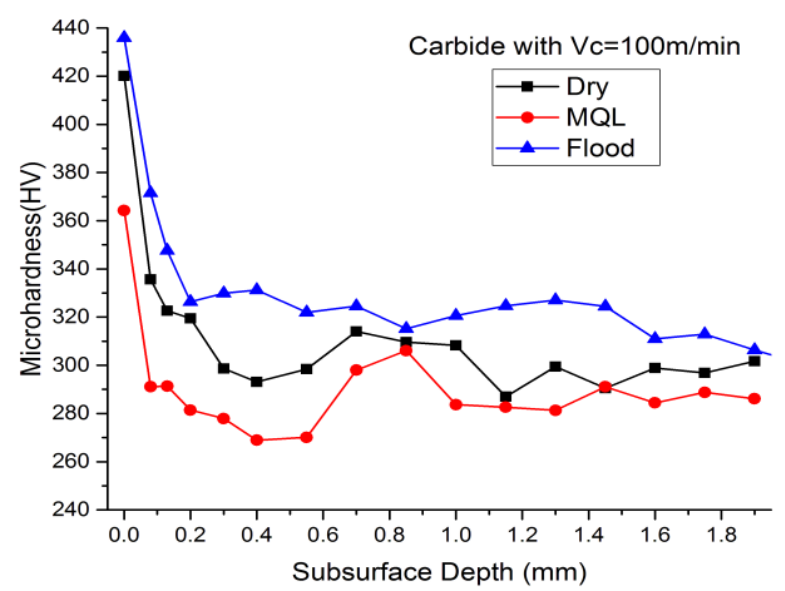

Fig. 3(a): Influence of cutting parameters microhardness using Carbide tool with $\mathrm{Vc}=100 \mathrm{~m} / \mathrm{min}$.

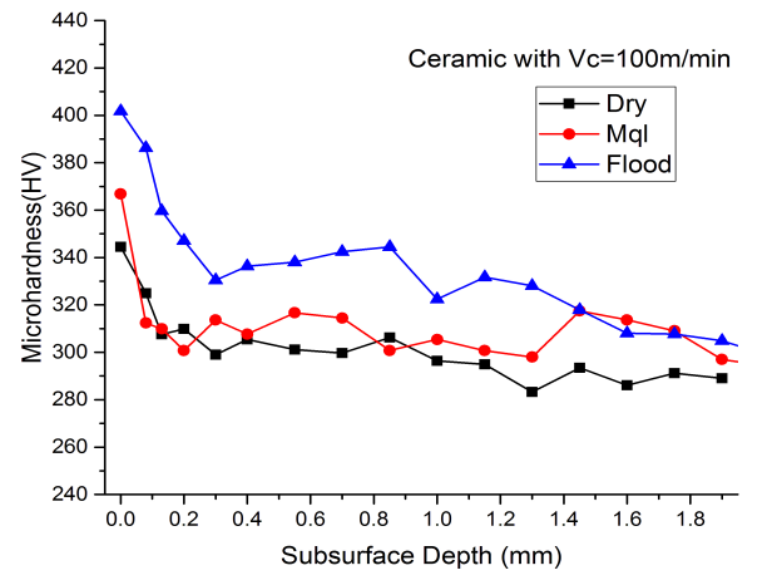

Fig. 3(b): Influence of cutting parameters microhardness using Ceramic tool with $V_{c}=100 \mathrm{~m} / \mathrm{min}$.

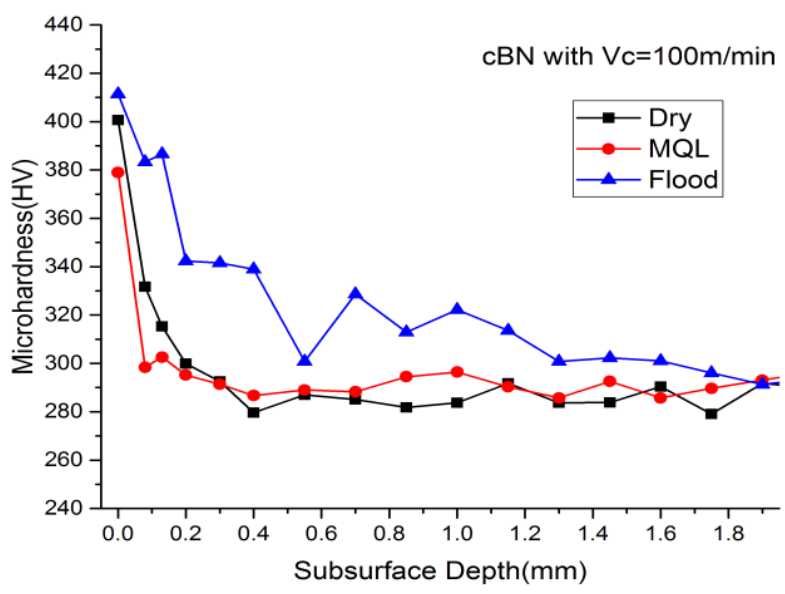

Fig. 3(c): Influence of cutting parameters microhardness using $c B N$ tool with $V c=100 \mathrm{~m} / \mathrm{min}$.

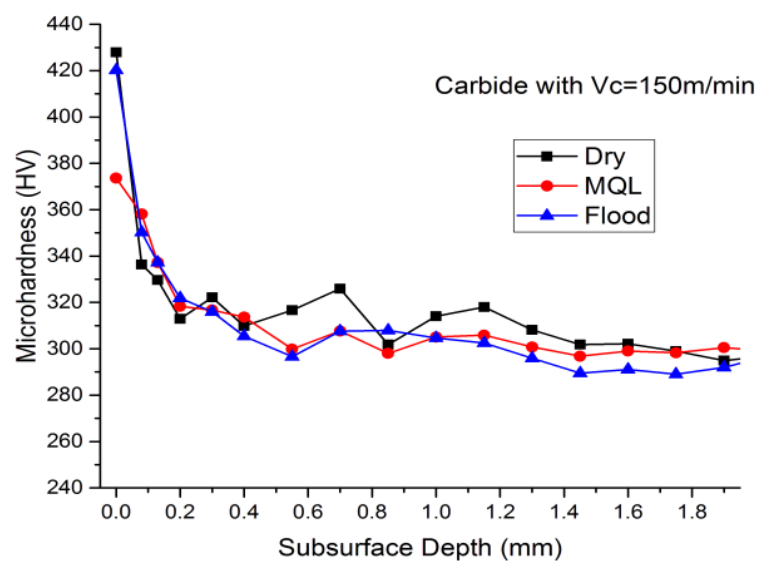

Fig. 3(d): Influence of cutting parameters microhardness using Carbide tool with $V_{c}=150 \mathrm{~m} / \mathrm{min}$.

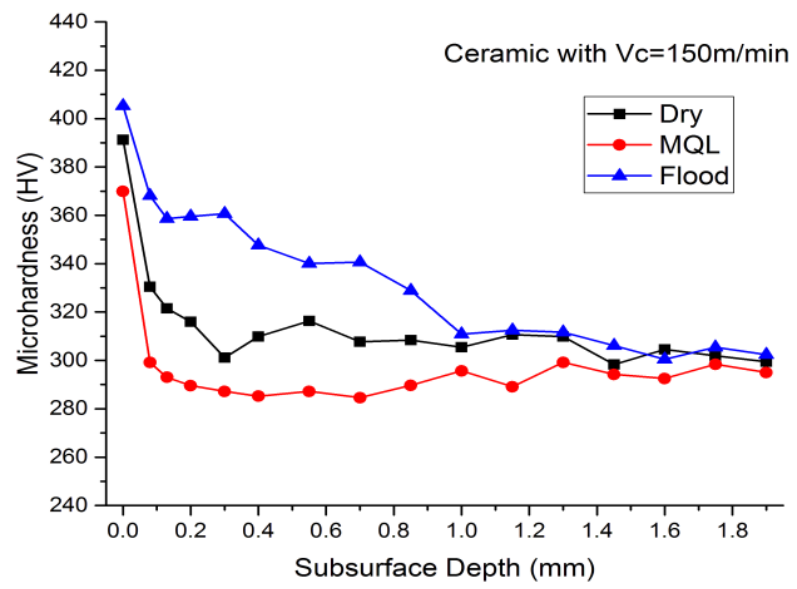

Fig. 3(e): Influence of cutting parameters microhardness using Ceramic tool with $V c=150 \mathrm{~m} / \mathrm{min}$. 


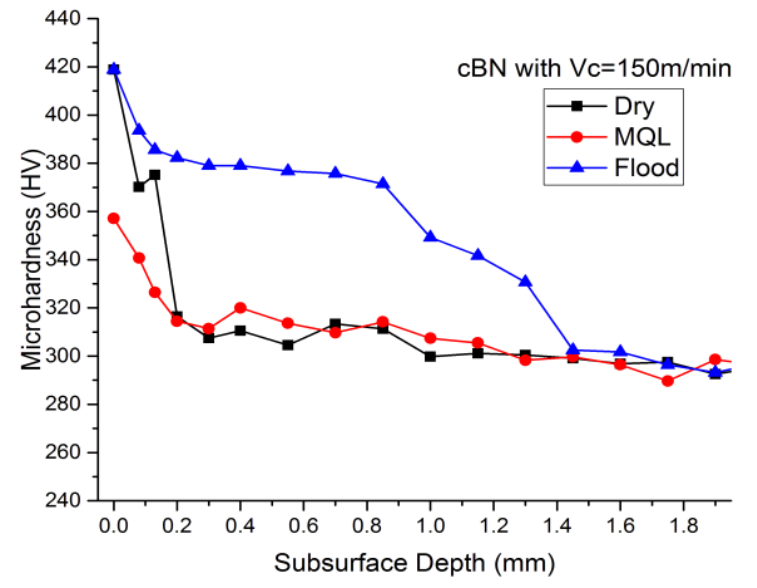

Fig. 3(f) Influence of cutting parameters microhardness using $c B N$ tool with $V c=150 \mathrm{~m} / \mathrm{min}$.

It can be noted from the illustrations that the machined surface is harder and gradually reduces towards the depth (i.e. at the subsurface) and reaching the normal bulk material hardness value. While machining at a cutting speed $(\mathrm{Vc})=100 \mathrm{~m} / \mathrm{min}$ with carbide insert, higher microhardess values were observed for flood cooling condition, on the other hand for MQL cutting conditions microhardness values observed were below the bulk materials average hardness values as presented in Fig.3a. The decrease in microhardness below the bulk material hardness value can be attributed to the neutralization of heat and strain effect in the subsurface [9]. While machining at a cutting speed of $100 \mathrm{~m} / \mathrm{min}$ with ceramic insert, lower microhardness were obsrved for dry and MQL cutting conditions, on the other hand higher microhardness was noted for flood cooling as indicated in Fig. 3b. For cBN tool at $\mathrm{Vc}=100 \mathrm{~m} / \mathrm{min}$., higher hardness values were observed deep into the subsurface i.e up to $1 \mathrm{~mm}$ depth; high hardness were recorded for flood cooling as indicated in Fig. 3c. At higher cutting speed $(\mathrm{Vc})=150 \mathrm{~m} / \mathrm{min}$ lower microhardness were observed for carbide and ceramic tool in MQL cutting conditon as shown in Fig. $3 \mathrm{~d} \&$ e. For $\mathrm{cBN}$ at $V_{c}=150 \mathrm{~m} / \mathrm{min}$ highest hardness at deep subsurface were found for flood cooling condition up to $1.4 \mathrm{~mm}$ depth; for dry and MQL cutting conditions the microhardness value

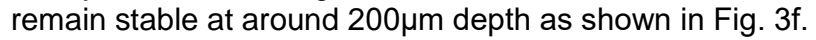

From Fig. 3 a,b \& c at cutting speed of $100 \mathrm{~m} / \mathrm{min}$; dry cutting condition showed better microhardness value for all tool materials. Similarly at higher cutting speed of $150 \mathrm{~m} / \mathrm{min}$; MQL cutting condition showed better microhardness value as compared with other two cutting conditions as indicated in Figs. $3 \mathrm{~d}$, e \& f. For all tool materials and cutting speeds higher microhardness were observed for flood cooling condition. The hardness values are found to be approximately 1.5 to 1.7 times of bulk material hardness.

\subsection{Tool Wear Analysis}

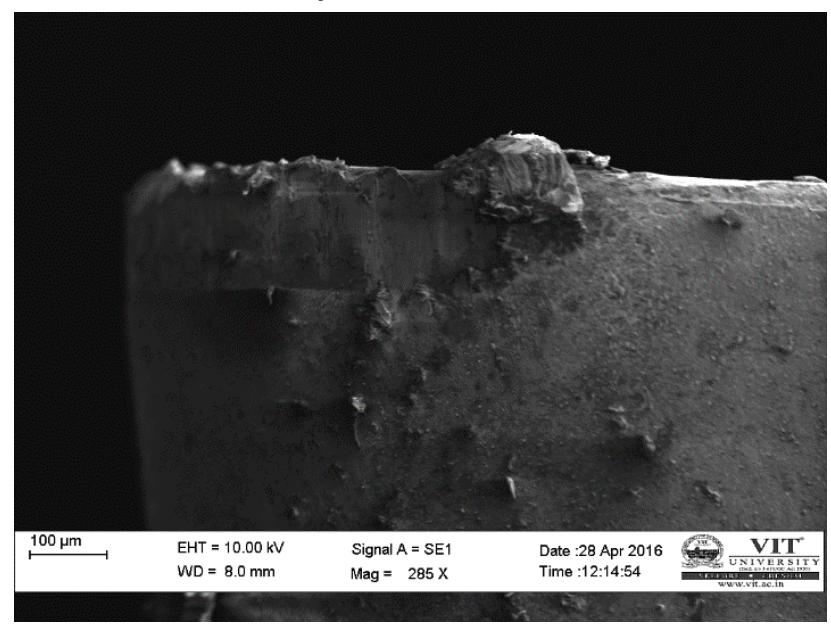

Fig. 4(a) Tool flank wear using Carbide tool with $V c=100 \mathrm{~m} / \mathrm{min}$ and dry cutting condition.

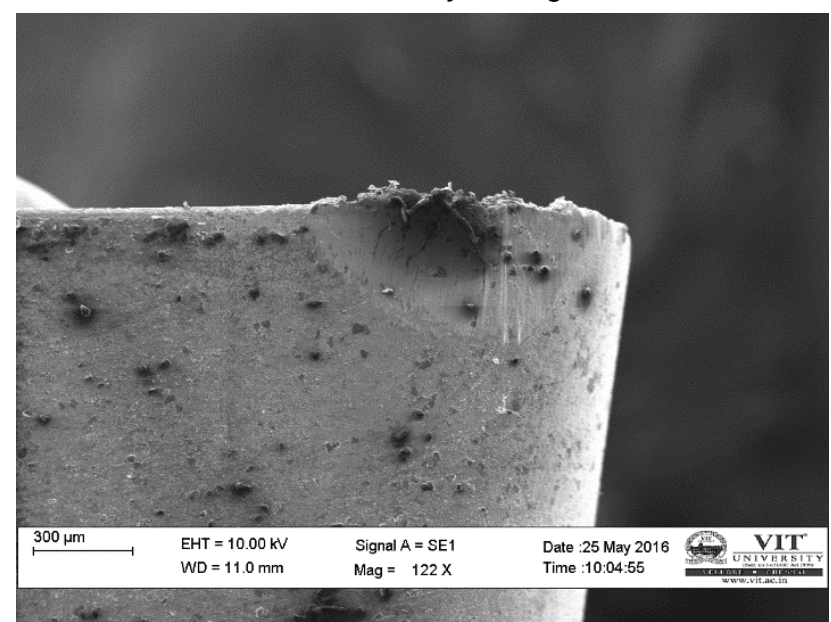

Fig.: 4(b) Tool flank wear using Carbide tool with $V c=150 \mathrm{~m} / \mathrm{min}$ and dry cutting condition.

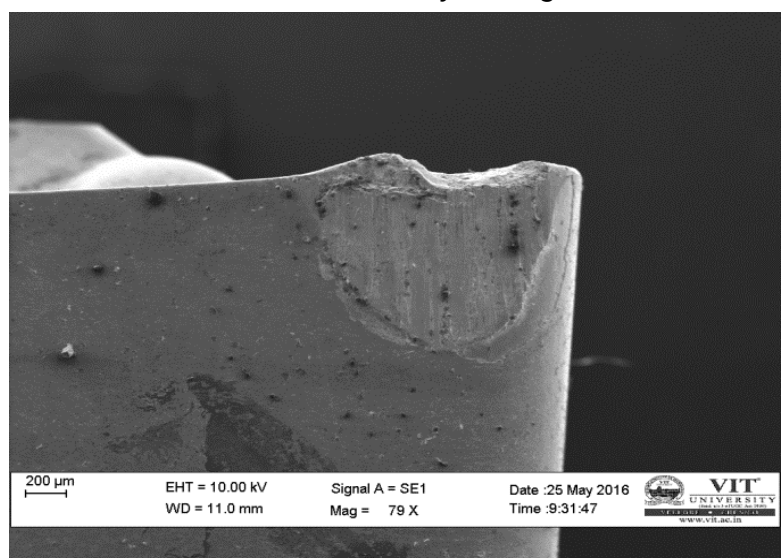

Fig. 4(c): Tool flank wear using Ceramic tool with $V c=100 \mathrm{~m} / \mathrm{min}$ and flood cooling condition. 


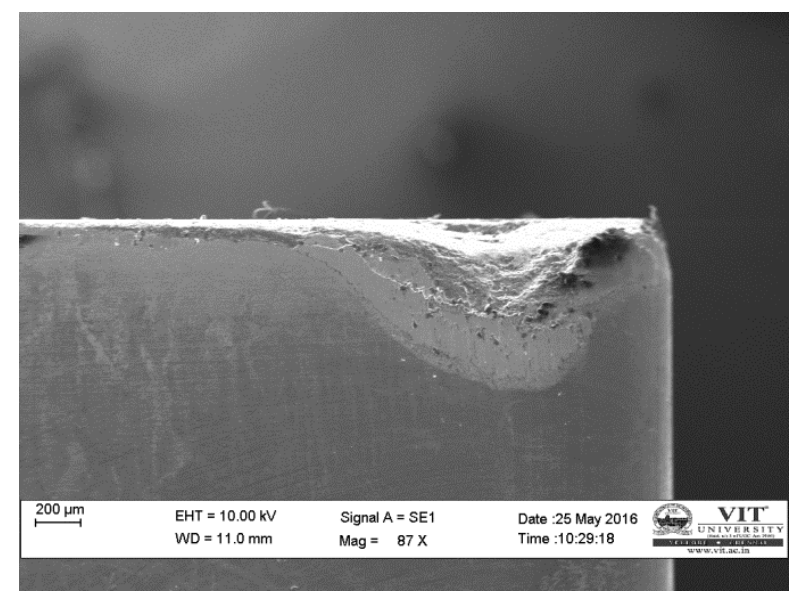

Fig. 4(d): Tool flank wear using Ceramic tool with $V c=150 \mathrm{~m} / \mathrm{min}$ and flood cooling condition.

It has been observed that flank wear is the prevailing wear mode in the experiments conducted which was initiated as a result of abrasion, notching, chipping and adhesion. During machining of Inconel 718 friction and heat at the machining zone is the common problem that adversely influences the tool life and surface integrities. Wear has occurred as presented in Fig. 4 a-d which are the consequence of notching and chipping for carbide and ceramic tool respectively.

Carbide tool at $\mathrm{Vc}=150 \mathrm{~m} / \mathrm{min}$ under dry cutting condition, exhibited strong chipping and notch wear, and it seems that a reasonable amount of tool material is lost on the tool face. This type of tool wear happens while machining at a high cutting speed and feed rate as shown in Fig. 4a. Further; machining with such worn tool causes generation of high cutting force and pressure at the cutting zone which affects on depth and degree of microhardness and surface quality.

While machining with Ceramic tool at $\mathrm{Vc}=100 \mathrm{~m} / \mathrm{min}$ under flood cooling condition, notching is the source of wear. Such type of wear pattern appears when tool material and material to be cut are very hard and brittle as shown in Fig. 4b. As ceramic material is having poor thermal conductivity property it doesn't play any significant role in heat conduction in metal cutting operation. Therefore the total heat generated during machining is carried out by bulk material and chip which results in high temperature generation in bulk material. During machining with flood cooling cutting condition due of high pressure flooding effect, hot bulk material experiences sudden quenching effect, which raises the bulk material hardness and brittleness and lowers the tool life.

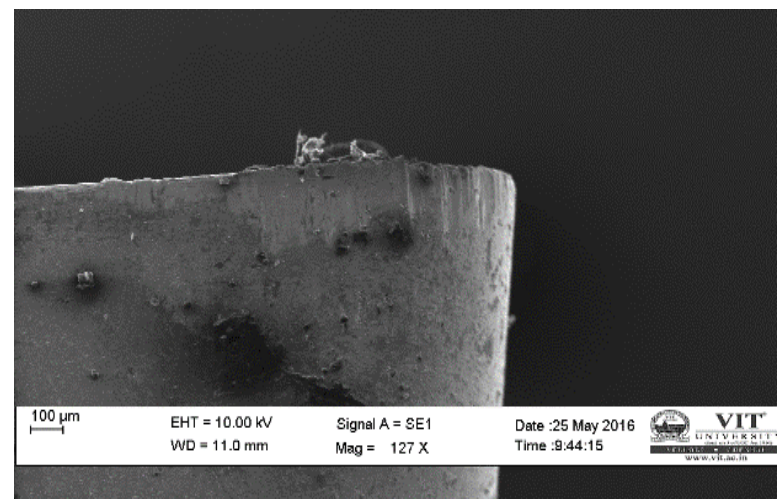

Fig. 5(a): Wear on $c B N$ tool at $V c=100 \mathrm{~m} / \mathrm{min}$ with $d r y$ cutting conditions.

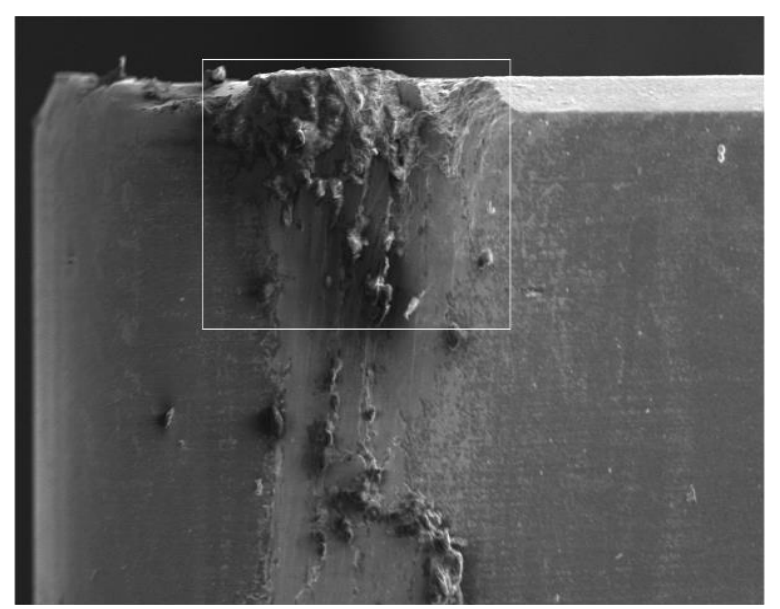

Fig. 5(b): Wear on $c B N$ tool at $V c=150 \mathrm{~m} / \mathrm{min}$ with dry cutting conditions.

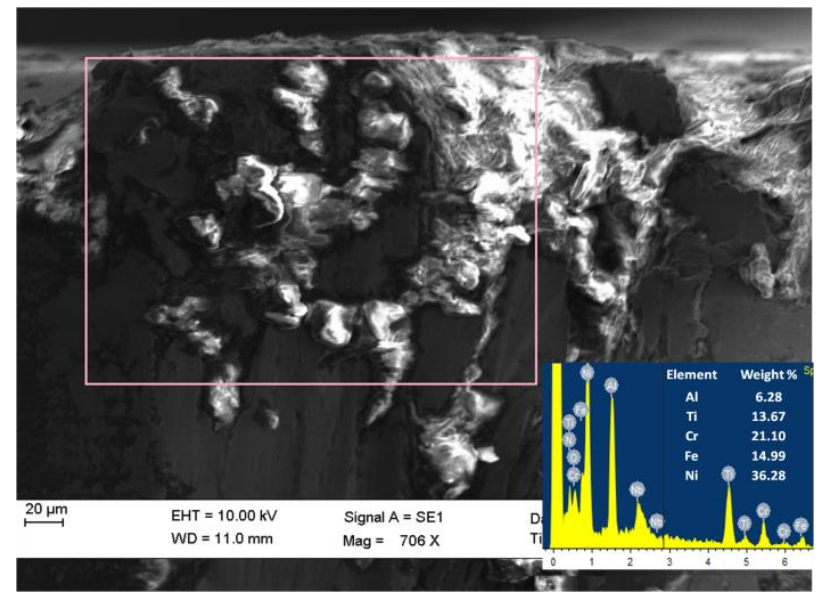

Fig. 5(c): Wear on EDAX analysis for $\mathrm{CBN}$ tool.

For cBN tool under dry cutting condition, adhesive wear is observed on flank face of tool as shown in Fig. 5(a-b). Adhesive wear occurs during frictional contact between two surfaces and usually referred as unwanted displacement and welding of wear debris and material compound from work material surface to tool face. From EDAX analysis, it is clear that foreign material (i.e work material) particles were welded on tool face; elements like $\mathrm{Ni}, \mathrm{Cr}$ and $\mathrm{Fe}$ were observed on the tool face as shown in Fig. 5c. Adhesive wear generally appears in dry cutting condition due to lack of lubrication and high temperature generation in such cutting condition. Such kind of wear causes poor shearing action and high plastic deformation during further machining that ends up in significant work hardening effect in work material.

\section{CONCLUSION}

Work hardening effect and wear mechanism observed while machining of Inconel 718 was reported in this paper. Experimental trails were conducted with flood coolant, MQL and dry cuttings conditions. Different combinations of wear mechanisms were noted, especially notch wear on flank face because of high work hardening tendency of Inconel718 material. Tool wear observed in the form of adhesion, abrasion and notching on tool/flank face through different wear mechanisms are referred to thermomechanical effect. It is noted that an increase in cutting force and temperature leads to formation of micro welds at the tool work interface. This results in reduction of tool strength and weakens the cutting edge, which finally causes plastic deformation and tool failure. Further, it has 
been inferred that, machining with MQL system has shown better results in terms of microhardness for all cutting speeds and tool materials, which indicates that a small quantity of lubrication is sufficient during machining of Inconel 718. Flood cooling conditions has shown higher microhardness on the surface as well as deep into the subsurface level. During flood cooling the high temperature zone (tool-work interface zone) experiences sudden cooling (quenching) effect which resulted in the higher surface micro hardness. In fact, the ceramic tool has shown lesser tool wear at both the cutting speeds (100 and 150 $\mathrm{m} / \mathrm{min}$.) under dry and MQL machining, but resulted in severe notching during flood cooling cutting condition. It was also noted that the carbide tool with high speed and dry conditions showed high notching which indicates that this tool is not suitable for such cutting conditions, whereas, the $\mathrm{cBN}$ insert has shown an adhesive wear at $\mathrm{Vc}=150 \mathrm{~m} / \mathrm{min}$ under dry cutting conditions.

\section{REFERENCES}

[Zhou 2012] Zhou, V. Bushlya, R. L. Peng, and J. Stahl. Identification of Subsurface Deformation in Machining of Inconel 718. Applied Mechanics and Materials, 117 - 119: 1681-1688.

[O. Çolak 2012] O. Çolak. Investigation on machining performance of Inconel 718 under high pressure cooling conditions. Journal of Mechanical Engineering, 58(11) : 683-690.

[Bushlya 2012] V. Bushlya, J. Zhou, and J. E. Ståhl. Effect of cutting conditions on machinability of superalloy inconel 718 during high speed turning with coated and uncoated PCBN tools. Procedia CIRP, 3: $370-375$.

[Smallman 1999] R. E. Smallman. A book for Modern Physical Metallurgy and Materials Engineering. Reed Educational and Professional Publishing Ltd, 6th Edition. UK.

[A Thakur 2014] A Thakur, A Mohanty, S. Gangopadhyay, K P Maity. Tool wear and chip characteristics during dry turning of Inconel 718. Procedia Material Science, 2: 2169 $-2177$

[Cantero JL 2013] J . L . Cantero , J . Díaz- ÁLvarez , M . H . Miguélez , N . C . Marín Analysis of tool wear patterns in finishing turning of Inconel 718. Wear, 297(1-2): 885 - 894.

[Ulutan D 2011] D. Ulutan and T. Ozel, (2011) Machining induced surface integrity in titanium and nickel alloys: A review. International Journal of Machine Tools and Manufacture, 51(3): 250-280.

[RS Pawade 2007] R. S. Pawade, S. S. Joshi, P. K. Brahmankar, and M. Rahman (2007) An investigation of cutting forces and surface damage in high-speed turning of Inconel 718. Journal of MaterialsProcessing Technology, 192-193: 139-146.
[E.O. Ezugu 2005] E. O. Ezugwu, D. a. Fadare, J. Bonney, R. B. Da Silva, and W. F. Sales. Modelling the correlation between cutting and process parameters in high-speed machining of Inconel 718 alloy using an artificial neural network. International Journal of Machine Tools Manufacture. 45(12-13): 1375-1385.

[X Ren 2016] X. Ren and Z. Liu. Influence of cutting parameters on work hardening behavior of surface layer during turning superalloy Inconel 718. doi:10.1007/s00170016-8350-9

[Yan 2013] Y. Fan, Z. Hao, M. Zheng, F. Sun, and S. Yang. Study of surface quality in machining nickel-based alloy Inconel 718. International Journal of Advanced Manufacturing Technology. 69(9-12): 2659 -2667. 